\title{
Ensino de Cartografia numa perspectiva inclusiva: quais as possibilidades de contribuição da Cartografia Tátil?
}

Helcio Ribeiro Campos ${ }^{*}$

\section{Resumo}

O artigo mostra que as técnicas e pressupostos teóricos já consagrados pela Cartografia convencional precisam ser adequados ao uso por parte de deficientes visuais, além de uma produção específica que atenda a esse público, constituindo a Cartografia Tátil. Sua exequibilidade, entretanto, ainda é restrita porque é um ramo do conhecimento recente, pouco conhecido, em formação, e que precisa ser divulgado para ser incorporado como realidade nos conteúdos escolares pertinentes - em especial na Geografia permitindo, desse modo, que alunos com deficiências visuais tenham uma nova possibilidade de inclusão social e escolar.

Palavras-chave: Cartografia Tátil; Cartografia; Inclusão escolar.

Teaching of Cartography in an inclusive perspective: what are the possibilities of Tactile Mapping contribution?

\section{Abstract}

The article shows that the techniques and theoretical concepts already established by conventional Cartography must be suitable for usage by the visually impaired, and a specific production that meets the public, constituting the Tactile Cartography. Its feasibility, however, is still restricted because it is a recent branch of knowledge, little known in training, and must be released as a

Professor do IFET - Instituto Federal de Educação, Ciência e Tecnoligia - Campus Barbacena. Mestre em Geografia Humana pela USP.

Geosul, Florianópolis, v. 27, n. 54, p 165-180, jul./dez. 2012 
CAMPOS, H.R. Ensino de Cartografia numa perspectiva inclusiva: quais...

reality to be incorporated in relevant school subjects - especially in Geography - allowing, therefore, that students with visual impairments have a new possibility for social inclusion and education.

Key words: Tactile Cartography; Cartography; Inclusion school.

\section{Introdução}

A Geografia é a disciplina que, na escola - e no cotidiano também - está associada ao uso da Cartografia. Embora seu uso não seja uma exclusividade geográfica, nela se assenta a responsabilidade pelo ensino do uso das ferramentas cartográficas, como a leitura de mapas, o que corresponde a uma "alfabetização cartográfica". Apesar de a Geografia ter sido sistematizada como ciência somente no século XIX e os mapas inventados séculos antes, a convergência entre ambas - Cartografia e Geografia -, no mundo escolar, está sedimentada.

Por que há tanta ligação entre tais ramos do conhecimento? A resposta aponta para a concepção de espaço geográfico como o conjunto de objetos e ações que revela práticas sociais dos diferentes grupos que vivem num determinado lugar, interagindo, lutando, sonhando, produzindo e (re)construindo continuamente seu espaço de vivência, como indicou Milton Santos ao longo de sua extensa e importante obra. Assim, o documento cartográfico é a concretização da realidade que ora se apresenta, sintetizando a imbricada rede de fatores que compõem e ajudam a explicar a dinâmica geográfica.

Se Geografia e Cartografia marcam uma parceria consagrada, a ideia de educação inclusiva já é mais recente e ainda carente de fortalecimento. Por isso, a questão central deste artigo é analisar o papel da Cartografia Tátil como elemento aglutinador e útil na consecução de uma escola integradora para alunos com cegueira e visão subnormal - a partir da apresentação de seus pressupostos teóricos e práticos -, além de divulgar, através de suas 
CAMPOS, H.R. Ensino de Cartografia numa perspectiva inclusiva: quais...

características, um caminho para a educação em nossa escala local e regional, pois a Cartografia Tátil deve ser mais conhecida e, depois disso, absorvida de modo pragmático nas salas de aula, principalmente pelos professores de Geografia. De acordo com a importância da Cartografia e de sua vertente, a Cartografia Tátil, segue-se um breve esclarecimento conceitual.

Joly (1990, p. 07-09) define Cartografia como a arte de conceber, de levantar, de redigir e de divulgar os mapas e menciona que isso implica, por parte do cartógrafo, um conhecimento aprofundado do assunto a ser cartografado e dos métodos de estudo que lhe são concernentes, além de uma familiaridade com os modernos procedimentos de criação e de divulgação dos mapas, desde o sensoriamento remoto até a cartografia computadorizada, passando pelo desenho manual e pela impressão. "Ela engloba, portanto, todas as atividades que vão do levantamento de campo ou da pesquisa bibliográfica até à impressão e à publicação do mapa" (p. 09). Assim, a cartografia é considerada, simultaneamente, uma ciência, uma arte e uma técnica, com o objetivo de representar a organização do espaço através dos mapas, “(...) os quais resultam de uma série de operações que fazem parte de um campo definido da atividade humana: a Cartografia" (DUARTE, 2002, p. 15).

Cartografia Tátil é a área específica da Cartografia dedicada ao desenvolvimento metodológico, à produção de material didático para a transmissão de conceitos geográficos, do meio ambiente e da vida em sociedade, bem como a sua aplicação em aula para alunos cegos e de baixa visão, para os quais os "mapas táteis" (ALMEIDA e LOCH, 2006, p. 03), ou seja, representações gráficas em textura e relevo que servem para orientação e localização de lugares e fenômenos geográficos.

A Cartografia Tátil é uma ramificação da Cartografia que se preocupa com a confecção de mapas e instrumentos cartográficos para pessoas com necessidades especiais, possibilitando ao deficiente visual uma maior percepção do mundo, facilitando a 
CAMPOS, H.R. Ensino de Cartografia numa perspectiva inclusiva: quais...

mobilidade e, por consequência, se transforma em uma poderosa ferramenta para o ensino de Geografia e de outras ciências.

Soma-se a essas vantagens e atribuições, uma preocupação: o fato importante de que o maior contingente da população com necessidades especiais ser o que apresenta deficiências visuais, de acordo com dados oficiais do IBGE (Censos de 2000 e de 2010). Além da precária incorporação dos estudantes com necessidades especiais nas escolas do Brasil, tal população foi contada por amostragem a cada 10 residências no Censo 2000. O Artigo 31 (estatísticas e coletas de dados) da Convenção Sobre o Direito das Pessoas com Deficiência, da ONU, determina a coleta de dados apropriados, ou seja, um Censo (IBGE, 2010).

O tema pessoas com deficiência foi pesquisado nos Recenseamentos brasileiros de 1872, 1890, 1900, 1920 e 1940. Em um período de mais de um século, a intensa evolução do conhecimento na área da saúde determinou importantes alterações no modo de fazer a investigação, no sentido de incorporar os novos conhecimentos e de aprimorar a forma de captação da informação. Depois de cerca de meio século ausente dos censos brasileiros, em 1991, o tema retornou através de uma única questão que investigava a deficiência física e mental. A metodologia passou para cinco questões, obtendo uma ampla combinação de tipos e de graus de deficiência, inclusive das pessoas com visão subnormal (IBGE, 2000 e 2010).

A promulgação da Lei $n^{0} 7$ 853, de 24 de outubro de 1989, trouxe, entre outras garantias legais, a obrigatoriedade da inclusão, nos censos nacionais, de questões específicas sobre as pessoas com deficiência. Esta informação é importante para subsidiar o planejamento de políticas públicas direcionadas a atender e facilitar a inclusão social desta população. Desde o planejamento do Censo 2000, o IBGE trabalhou em parceria com a Coordenadoria Nacional para Integração da Pessoa Portadora de Deficiência - CORDE, na época, subordinada ao Ministério da Justiça, atualmente Secretaria Nacional de Promoção dos Direitos da Pessoa com Deficiência, tanto nos testes das perguntas nas provas-piloto, no Censo 
CAMPOS, H.R. Ensino de Cartografia numa perspectiva inclusiva: quais...

Experimental, no desenho definitivo do questionário e nas análises dos resultados do Censo. Desde então, o IBGE e a CORDE vêm trabalhando juntos visando o aperfeiçoamento do levantamento de informações estatísticas sobre as pessoas com deficiência (Secretaria de Direitos Humanos, 2010).

A tabela abaixo é representativa da gravidade do problema no Brasil, concernente a várias áreas, dentre as quais a educação inclusiva, focalizada neste artigo.

TABELA 1: População residente por tipo de deficiência - Brasil $-2000$

\begin{tabular}{|c|c|}
\hline Tipo de deficiência & População residente \\
\hline Mental & 2.844 .937 \\
\hline Física & 1.416 .060 \\
\hline Visual & 16.644 .842 \\
\hline Auditiva & 5.735 .099 \\
\hline Motora & 7.939 .784 \\
\hline
\end{tabular}

Fonte: IBGE, Censo Demográfico 2000.

Traçadas as linhas introdutórias que apresentam conceitos e especificidades acerca das relações entre a Cartografia Tátil e as questões sobre deficiência, abrir-se-á espaço para a discussão específica da contribuição que pode ser obtida através do conhecimento cartográfico geral e do conhecimento cartográfico destinado a portadores de deficiência visual.

\section{A questão da comunicação através dos mapas e a produção cartográfica tátil}

O desafio que se instala é como fazer alguém ter a percepção de um espaço e de sua representação (o mapa)? E além: como permitir o acesso de pessoas com deficiências visuais a um material que se baseia quase que exclusivamente em imagens? A 
CAMPOS, H.R. Ensino de Cartografia numa perspectiva inclusiva: quais...

Cartografia tradicional não serve a esses deficientes. Isso ocorre porque o canal visual é o mais abrangente, sendo mais eficaz na transmissão de informações que os demais sentidos - tátil, auditivo, olfativo e gustativo - que são complementares.

Além disso, há um repertório de cores e símbolos padronizados para uso cartográfico em todo o mundo (as convenções cartográficas), constituindo uma face muito marcante da Cartografia Temática. "O objetivo dos mapas temáticos é o de fornecer, com o auxílio de símbolos qualitativos e/ou quantitativos dispositivos sobre uma base de referência, geralmente extraída de mapas topográficos" (JOLY, 1990, 74-75).

Entende-se Cartografia Temática como o conjunto de preocupações e operações que visam representar graficamente um conjunto de dados de certa área, podendo ser chamada também de Cartografia Especial. Os mapas da Cartografia Temática têm, em geral: 1) uso limitado quanto ao tempo, pois trabalham com dados que se renovam com rapidez; 2) confecção realizada por pessoas não especializadas em Cartografia; 3) as cores e suas tonalidades podem ter significado quantitativo; 4) utilização de símbolos gráficos especialmente planejados para facilitar a compreensão de diferenças quantitativas; 5) pouca utilização como base para outras representações.

Nesse ramo do conhecimento, Jacques Bertin (1977, p. 177), um dos ícones da comunicação gráfica, afirma que o cartógrafo precisa analisar a natureza quantitativa, ordenada ou diferencial dos dados a serem transcritos e selecionar a melhor variável visual ${ }^{1}$ (tamanho, valor, cor, textura, orientação e forma), a fim de possibilitar uma leitura eficiente do mapa. Bertin só aceita a normatização de signos convencionais, visando a uma economia de tempo e lugar, obedecendo, em primeiro lugar, à lei fundamental

${ }^{1}$ Considera-se variável visual toda diversificação imposta aos símbolos, de modo a traduzir uma informação para a linguagem gráfica, de acordo com Duarte (2002, p. 191). Ver também Martinelli, M. A sistematização da Cartografia Temática (2007, p. 193-220). In: Almeida, 2007. 
CAMPOS, H.R. Ensino de Cartografia numa perspectiva inclusiva: quais...

da representação gráfica ( graphique), que consiste em não destruir as relações entre os elementos representados; e, em segundo, à lei da memorização, que é proporcional à repetição da convenção e é inversamente proporcional ao número de convenções.

Em vez de citar Bertin, utilizaremos o didatismo de Duarte (2002, p. 191-193) para melhor mostrar o significado das variáveis visuais. Ele explica que o tamanho representa o tamanho da dimensão do símbolo, sendo apropriado para informações quantitativas. A cor corresponde à sensação subjetiva das pessoas ao perceberem uma radiação eletromagnética. A variável valor diz respeito à diversificação da tonalidade de uma cor, indicando valores fortes e fracos. Já a forma, relaciona-se ao feitio ou à configuração dos símbolos, podendo ser usadas variações geométricas, combinações de traços e figuras. A orientação corresponde à inclinação do traço nas representações em uma só cor, quando são usadas hachuras e tramas, variando a posição entre vertical, oblíqua e horizontal. Por fim, a granulação é uma repartição do preto no branco, sendo uma variável visual pouco usada.

Ao identificar essas variáveis (tamanho, valor, cor, textura, orientação e forma), Bertin criou uma sistematização da linguagem cartográfica. Apesar de sua proposta destinar-se à representação gráfica como recurso visual, muitos dos conceitos de semiologia gráfica e de suas aplicações práticas podem ser convertidos para a representação tátil. 
CAMPOS, H.R. Ensino de Cartografia numa perspectiva inclusiva: quais...

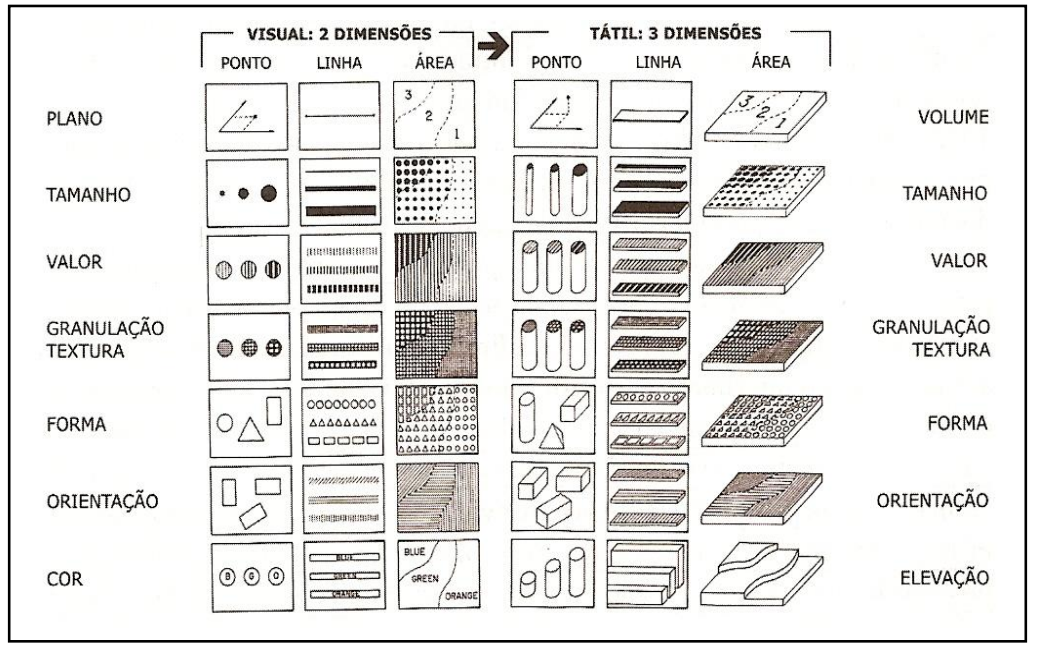

FIGURA 1: As variáveis gráficas na forma tátil Fonte: ALMEIDA, Regina Araújo, 2007, p. 129.

"A semiologia gráfica constitui-se numa linguagem visual, cujas bases são a percepção e lógica. É um instrumento que possibilita ver para aprender". Bertin (1977, p. 176) explica que a semiologia gráfica “(...) utiliza as propriedades do plano para revelar as relações de semelhança, de ordem ou de proporcionalidade entre conjuntos de dados. A semiologia gráfica é o nível monossêmico do mundo das imagens". A criança percebe as igualdades e as diferenças, as ordens e, mais tarde, as proporções. A característica mais importante da semiologia gráfica é, sem dúvida, seu caráter monossêmico, através do qual um círculo é percebido como diferente de uma cruz; o vermelho é diferente do azul; "o grande, o médio e o pequeno são ordenados, assim como 10, 20, 30 e 40 são proporcionais, de modo universal, sem necessidade de recorrer a uma legenda" (LE SANN, 2007, p. 103. In: ALMEIDA, 2007). 
CAMPOS, H.R. Ensino de Cartografia numa perspectiva inclusiva: quais...

As cores e os símbolos cartográficos não podem ser substituídos com as facilitações que a linguagem escrita teve ao ser passada para o sistema braile, inventado por Louis Braile, na França, em 1829. A imagem espacial precisa de uma linguagem gráfica própria e enquanto os materiais cartográficos adaptados e disponíveis forem escassos, haverá uma limitação educacional imposta.

A criação do Sistema Braille colocou ao alcance das pessoas cegas o acesso à educação e à cultura, abrindo espaço para os diferentes campos do saber humano. A princípio, e durante muitos anos, o sistema Braille constituiu o mais valioso procedimento empregado no atendimento educacional aos cegos. Era a base da instrução, aquisição de conhecimentos, do saber e da cultura intelectual sob todas as suas formas (história, filosofia, psicologia, teologia, matemáticas, filologia, literatura, direito). Os benefícios do sistema estenderam-se progressivamente, à medida que as aplicações revelavam todas as suas potencialidades (LEITE, 2003).

Antes de se chegar à fase dos trabalhos com mapas táteis, como se faz também com mapas convencionais, os alunos devem passar pelo aprendizado de conceitos prévios básicos, como os de localização e de orientação, escalas, decodificação e leitura de mapas. "É função da escola preparar o aluno para compreender a organização espacial da sociedade, o que exige o conhecimento de técnicas e instrumentos necessários à representação gráfica dessa organização" (ALMEIDA, 2001, p. 17).

Na prática, porém, existem diferenças que não podem ser abandonadas. A diferença de resolução entre o olho humano e o tato é enorme, pois o este é capaz de observar menos detalhes e percebe as partes para, só depois, perceber o todo. Por esses motivos os mapas táteis têm uma simplificação quanto ao número de informações (a generalização) e têm escalas grandes para obter mais detalhamento.

Assim, “(...) alguns problemas a serem evitados na cartografia convencional tornam-se qualidades e condições necessárias para o design de mapas táteis eficazes" (ALMEIDA, 
CAMPOS, H.R. Ensino de Cartografia numa perspectiva inclusiva: quais...

2007: p. 125). A mesma autora indica dosar a carga de um mapa, sendo preferível fazer vários mapas a concentrar informações em apenas um. Além disso, o tamanho de cada maquete, gráfico ou mapa não deve ultrapassar $50 \mathrm{~cm}$, já que o campo abrangido pelas mãos é muito restrito em comparação com o campo visual (2007: p. 137).

As variáveis visuais desenvolvidas por Bertin (1977) foram transformadas em tridimensionais, perceptíveis através do tato. É o que se dá, por exemplo, com o uso da cor para usuários de mapas que sejam cegos. Nesse caso, texturas diferentes substituem as cores. Contudo, as regras gerais de tratamento das informações - se são qualitativas, quantitativas e ainda ordenadas, seletivas e associativas - como se faz em mapas convencionais, valem também para mapas táteis.

A construção dos mapas táteis tem sido feita mediante a utilização dos seguintes materiais e técnicas, dentre outros: alumínio; colagem; cópias em plástico na máquina Thermoform; cópias em serigrafia (silkscreen); impressora braile conectada ao computador com capacidade de impressão de representações gráficas; uso de papel microcapsulado, um tipo de papel que, ao ser aquecido em certa temperatura, faz com que a tinta de impressão (de impressoras a jato de tinta convencionais) expanda-se, formando textura e, assim, o mapa impresso torna-se um mapa tátil.

A despeito das técnicas supracitadas, as etapas pedagógicas prévias para a decodificação e leitura dos mapas táteis (o último estágio a ser alcançado), como a introdução das variáveis gráficas em relevo, por exemplo, têm importância capital para a consecução de uma eficiente alfabetização cartográfica (o ensino de mapas, a compreensão dos símbolos etc.), como preconizam os Parâmetros Curriculares Nacionais de Geografia (1997), ao indicar a Cartografia como um instrumento de aproximação dos lugares e do mundo para o Terceiro Ciclo. Ainda assim, Almeida (2001, p. 18) afirma que apesar do destaque que tal documento conferiu à Cartografia, ele apresenta o mesmo equívoco encontrado nos livros didáticos, ao “(...) concentrar o assunto em um único tópico do 
CAMPOS, H.R. Ensino de Cartografia numa perspectiva inclusiva: quais...

programa curricular, como se a representação pudesse ser separada dos conteúdos representados".

Além de tudo o que já foi exposto e analisado, é ponto pacífico entre os geógrafos concordar que uma cidadania plena precisa, também, abarcar a linguagem e o conhecimento cartográficos. Os exemplos que endossam esta ideia são provenientes de Pontuschka et al (2009, p.326), ao afirmar que "(...) tanto os mapas murais como o atlas, na condição de instrumentos pedagógicos, deveriam ser presença obrigatória nas salas de aula de Geografia”. Consideram também que “(...) é necessário ter iniciação no domínio da linguagem cartográfica, que foi enriquecida pelas teorizações sobre a semiologia", além de destacarem positivamente teses e dissertações brasileiras que versam sobre a cartografia escolar e que conferem importância a uma iniciação ou alfabetização cartográfica.

Para finalizar com uma "postura oficial", os Parâmetros Curriculares Nacionais: História e Geografia (1997, p. 62), têm o seguinte objetivo, dentre outros: "saber utilizar a linguagem cartográfica para obter informações e representar a espacialidade dos fenômenos geográficos". A questão a ser resolvida em todo o país é como adequar discurso com cidadania real, sem deixar de lado a inclusão escolar e sem fechar os olhos para a lamentável situação da educação brasileira. Nesse contexto, sem ilusões, alguns exemplos podem ser citados e seguidos quanto ao desenvolvimento e quanto às possibilidades da Cartografia Tátil.

Portanto, a questão da incorporação de conhecimentos cartográficos na escola ultrapassa a ideia dos saberes específicos da Cartografia Tátil, estendendo-se para os rumos das políticas públicas, dentre outros.

\section{Considerações finais: novos recursos e cidadania}

A preocupação com recursos gráficos na forma tátil é muito recente no Brasil, com avanços consideráveis apenas nos anos 1990. Dentre as ações mais proeminentes, é justo destacar o 
CAMPOS, H.R. Ensino de Cartografia numa perspectiva inclusiva: quais...

trabalho de Almeida (1993), responsável pela dinamização do LEMADI - Laboratório de Ensino de Material Didático - que funciona na USP, além de outras instituições que também desenvolvem projetos similares, como a PUCRS. Na UFSC está o Laboratório de Cartografia Tátil e Escolar - LABTATE, além das contribuições vindas da UNESP e da UFRJ, que têm trabalhos com sintetizadores de voz premiados com o $1^{\circ}$ lugar no Simpósio IberoAmericano de Educação Cibernética, em julho de 2005, em Orlando, Estados Unidos. Isso possibilita uma valorização crescente também dos demais sentidos presentes nos deficientes visuais, o que indica a chegada de uma Cartografia Multissensorial em substituição à Cartografia Tátil, segundo o vaticínio de muitos de seus estudiosos.

As pesquisas, contudo, ainda precisam ocupar uma série de lacunas - indica ALMEIDA (2007: p. 120) - a saber: legibilidade dos símbolos; normatização da linguagem gráfica; percepção e interpretação das representações gráficas pelo tato; treinamento necessário para a utilização de mapas e gráficos etc.

Os mapas na forma tátil poderiam ser úteis em várias situações cotidianas, como no caso da orientação e da mobilidade dos deficientes visuais em ambientes externos e internos, proporcionando eficiência e independência (NOVI, 1996: p. 54). Isso provocaria uma equidade no uso do espaço público de circulação, vias e logradouros; e também garantiria o direito universal à acessibilidade. Tais garantias constam como princípios da Política Nacional de Mobilidade Urbana (MINISTÉRIO DAS CIDADES, 2005: p. 18), porém não se efetivam.

Produzir direitos sugere um avanço, mas não garante sua exequibilidade. É o que ocorre, por exemplo, com a Constituição Federal de 1988, em seu artigo $5^{\circ}$ do capitulo I, no qual se afirma que “(...) todos são iguais perante a lei, sem distinção de qualquer natureza, garantindo-se aos brasileiros (...) a inviolabilidade do direito à vida, à liberdade, à segurança e à propriedade". No entanto, nem todos têm acesso aos equipamentos sociais e à infraestrutura ofertados pelo Estado. 
CAMPOS, H.R. Ensino de Cartografia numa perspectiva inclusiva: quais...

As políticas públicas para a educação, para o desenvolvimento urbano etc., apresentam falhas de atendimento aos direitos de cidadania que constam em leis brasileiras em diferentes instâncias governamentais (ALMEIDA e LOCH, 2006: p. 02).

Dentro do campo mais específico da Educação Especial, a Lei de Diretrizes e Bases da Educação Nacional - LDBEN - de 1996, afirma, em seu artigo 58, que "haverá, quando necessário, serviços de apoio especializado, na escola regular, para atender às peculiaridades da clientela de educação especial". Quando não for possível a integração do aluno nas classes comuns de ensino regular, esse atendimento educacional deve ser feito em classes especializadas denominadas "Salas de Recursos". No artigo seguinte aponta que os sistemas de ensino assegurarão a tais alunos “(...) currículos, métodos, técnicas, recursos educativos e organização específicos, para atender às suas necessidades", além da presença de "professores com especialização adequada e capacitados para a integração desses educandos nas classes comuns".

$\mathrm{Na}$ situação de ensino-aprendizagem de Geografia, os Parâmetros Curriculares (1997) orientam para a utilização de esquemas, maquetes, mapas e gráficos como recursos pedagógicos, bem como fotos, vídeos e desenhos para que os alunos possam compreender os fenômenos, processos históricos e sociais, e não somente para alunos com necessidades especiais, como para os demais.

Exposto isto, torna-se patente a incongruência entre as garantias legais e a oferta de oportunidades a todos. No caso dos serviços educacionais, há uma sutileza entre os extremos, pois o direito à escola é oferecido ao deficiente visual, mas com restrições oriundas da acessibilidade - nos transportes, na via pública, na arquitetura - e do ensino, como no caso da aprendizagem dos saberes geográficos.

Por isso, mostrar as características da Cartografia Tátil e suas possibilidades de melhorar o acesso à informação espacial na 
CAMPOS, H.R. Ensino de Cartografia numa perspectiva inclusiva: quais...

escola constituíram uma meta a ser alcançada neste texto, além de uma sugestão para que sua bandeira seja incorporada em nossas escolas.

As questões aqui levantadas indicam que o conhecimento e o debate acerca da Cartografia Tátil precisam avançar, até alcançar a comunidade escolar de forma ampla. Isso demonstra também que existem temáticas que dominam a formação de professores e que são fundamentais e prementes para a escola - como no caso da Geografia, que trabalha diretamente com o conhecimento cartográfico.

Apesar disso, a "alfabetização cartográfica" será mais rica e estimulada com a contribuição das demais áreas do saber. Portanto, as demandas de cada ciência precisam de espaço e debate como um meio que otimiza a qualidade escolar.

\section{Referências bibliográficas}

ALMEIDA, Regina Araújo. A Cartografia tátil e o deficiente visual: uma avaliação das etapas de produção e uso do mapa. São Paulo: USP, 1993 (Tese de Doutorado).

ALMEIDA, Regina Araújo. "A Cartografia Tátil no ensino de Geografia: teoria e prática". In: ALMEIDA, Rosângela Doin (Org.). Cartografia escolar. $1^{a}$ edição. São Paulo: Contexto, 2007, p. 119-144.

ALMEIDA, Rosângela Doin. Do desenho ao mapa: iniciação cartográfica na escola. $1^{\text {a }}$ edição. São Paulo: Contexto, 2001, 120 p.

ALMEIDA, Rosângela Doin (Org.). Cartografia escolar. $1^{\mathrm{a}}$ edição. São Paulo: Contexto, 2007, 224 p.

ALMEIDA, Luciana C. e LOCH, Ruth. Uma cartografia muito especial a serviço da inclusão social. UFSC, 2006 (Congresso Brasileiro de Cadastro Técnico Multifinalitário). 
CAMPOS, H.R. Ensino de Cartografia numa perspectiva inclusiva: quais...

BRASIL. Constituição da República Federativa do Brasil 1988. Disponível em: http://www.presidencia.gov.br. Acesso em $15 / 11 / 2011$.

BERTIN, Jacques. La graphique et le traitement graphique de l'information. Paris, Flammarion, 1977, 273 p.

DUARTE, P. Araújo. Cartografia temática. $2^{\mathrm{a}}$ edição. Florianópolis: Editora da UFSC, 2002, 208 p.

IBGE. Censo demográfico - 2000 e 2010. Disponível em: http://www.ibge.gov.br. Acesso em 20/10/2011.

JOLY, Fernand. A cartografia. $1^{\text {a }}$ edição. Campinas: Papirus, 1990, $136 \mathrm{p}$.

LE SANN, Janine G. "Metodologia para introduzir a Geografia no Ensino Fundamental". In: ALMEIDA, Rosângela Doin (Org.). Cartografia escolar. $1^{a}$ edição. São Paulo: Contexto, 2007, p. 95-118.

LEITE, Cristiane das Graças. A alfabetização de adultos portadores de deficiência visual. Revista Benjamim Constant, Rio de Janeiro, RJ. Edição 24, abril de 2003.

MINISTÉRIO DAS CIDADES. Mobilidade urbana é desenvolvimento urbano! Brasília, 2005.

MINISTÉRIO DA EDUCAÇÃO E CULTURA. Lei de Diretrizes e Bases da Educação Nacional - LDBEN. Brasília, 1996.

NOVI, Rosa M. Orientação e mobilidade para deficientes visuais. $1^{a}$ edição. Londrina: Cotação da Construção, 1996, 84p.

OLIVEIRA, Ariovaldo U. Para onde vai o ensino de Geografia? $1^{a}$ edição. São Paulo: Contexto, 1990, 144 p. 
CAMPOS, H.R. Ensino de Cartografia numa perspectiva inclusiva: quais...

PONTUSCHKA, Nídia N. e OLIVEIRA, A. Umbelino de (Org.).

Geografia em perspectiva. $1^{a}$ edição. São Paulo: Contexto, 2002, $383 \mathrm{p}$.

PONTUSCHKA, Nídia et al. Para ensinar e aprender Geografia. $3^{\text {a }}$ edição. São Paulo: Cortez, 2009, 383 p.

SECRETARIA DE DIREITOS HUMANOS. Pessoas com deficiência - 2010 . Disponível em: http://www.direitoshumanos.gov.br. Acesso em 05/01/2012.

SECRETARIA DE ENSINO FUNDAMENTAL. Parâmetros Curriculares Nacionais: História e Geografia. Brasília: MEC/SEF, 1997.

Recebido em abril de 2011 Aceito em março de 2012 